\title{
Influence of left ventricular ejection fraction on morbidity and mortality after aortic root replacement
}

\author{
Nathaniel B. Langer, MD, MSc, Masahiko Ando, MD, PhD, MPH, Michael Simpson, BA, \\ Benjamin S. van Boxtel, MD, Robert A. Sorabella, MD, Virendra Patel, MD, MPH, Isaac George, MD, \\ Craig R. Smith, MD, and Hiroo Takayama, MD, $\mathrm{PhD}$
}

\section{ABSTRACT}

Objective: To better understand morbidity and mortality in patients with a low left ventricular ejection fraction (LVEF) undergoing aortic root replacement.

Methods: All patients who underwent aortic root replacement at our institution between 2005 and $2013(n=595)$ were retrospectively reviewed and included in the study. The primary outcome was mortality. Secondary outcomes were inhospital mortality and perioperative morbidity. Restricted cubic spline analysis showed a relatively linear inverse relationship between LVEF and the hazard ratio for mortality in patients with an LVEF $<50 \%$ with no unique cutoff. Therefore, LVEF was treated as a continuous variable. Patients were divided into 3 groups (LVEF $<40 \%$, LVEF $40 \%-49 \%$, and LVEF $\geq 50 \%$ ) in order to illustrate the impact of LVEF on mortality.

Results: LVEF $<40 \%$ patients had greater in-hospital mortality (14.0\% vs $5.0 \%$ vs $1.0 \%, P<.001)$ and longer median hospital and intensive care unit stays $(10.5$ vs 8 vs 6 days, $P<.001$ and 4 vs 2 vs 2 days, $P<.001)$ than patients with LVEF $40 \%$ to $49 \%$ or greater than $50 \%$, respectively. Patients with LVEF $<40 \%$ had more reoperations for bleeding ( $18 \%$ vs $5.0 \%$ vs $5.8 \%, P=.004)$, postoperative respiratory failure ( $16 \%$ vs $6.7 \%$ vs $4.9 \%, P=.008)$, and need for mechanical circulatory support $(8.0 \%$ vs $5.0 \%$ vs $1.4 \%, P=.005)$. Using multivariable Cox proportional hazards analysis, we found that reduced LVEF, age, previous, cardiac surgery, and type A dissection were independent predictors of mortality.

Conclusions: Reduced LVEF negatively impacts mortality as well as in-hospital death and perioperative morbidity after aortic root replacement. Careful patient selection and risk discussion are vital in this high-risk population. (J Thorac Cardiovasc Surg 2019;158:984-91)

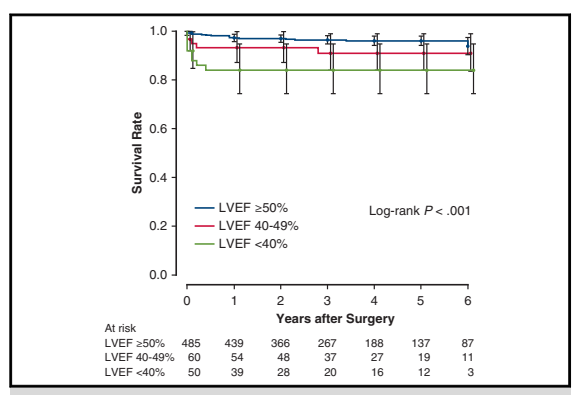

Kaplan-Meier analysis of survival by left ventricular ejection fraction.

\section{Central Message}

Patients with reduced left ventricular ejection fraction have increased morbidity and mortality after aortic root replacement. Careful patient selection and counseling are critical.

\section{Perspective}

The impact of reduced left ventricular ejection fraction (LVEF) on outcomes after aortic root replacement is not well defined. This study reports that decreasing LVEF is associated with markedly greater mortality and postoperative morbidity, highlighting the need for careful patient selection and counseling for what is often a prophylactic operation.

See Commentaries on pages 992 and 994.
Aortic root replacement (ARR) is the standard surgical procedure for patients with aortic root aneurysms, as well as select patients with a Stanford type A aortic dissection or endocarditis. Despite the surgical complexity, continued evolution of operative technique and postoperative care

From the Division of Cardiac, Thoracic, and Vascular Surgery, Columbia University College of Physicians and Surgeons, New York, NY.

Received for publication April 13, 2018; revisions received Oct 7, 2018; accepted for publication Oct 26, 2018; available ahead of print Dec 18, 2018.

Address for reprints: Hiroo Takayama, MD, PhD, Columbia University College of Physicians and Surgeons, 177 Fort Washington Ave, 7GN-435, New York, NY 10032 (E-mail: ht2225@cumc.columbia.edu).

$0022-5223 / \$ 36.00$

Copyright (c) 2018 by The American Association for Thoracic Surgery

https://doi.org/10.1016/j.jtcvs.2018.10.147 have significantly improved clinical outcomes. ${ }^{1-6}$ Although several studies have identified general risk factors, including emergent surgical indications, reoperation, New York Heart Association functional class, and pre-existing major organ dysfunction, there have been no studies specifically examining the impact of left ventricular ejection fraction (LVEF) on outcomes after aortic root

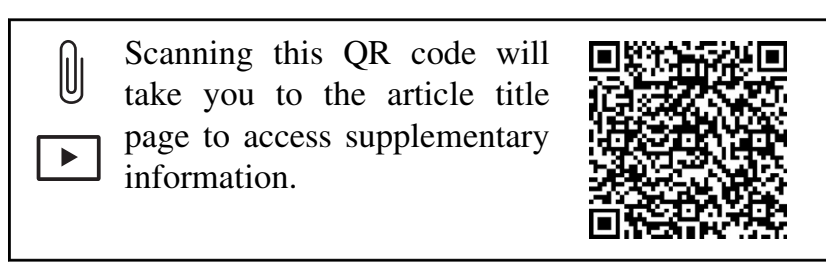




\section{Abbreviations and Acronyms \\ $\mathrm{ARR}=$ aortic root replacement \\ $\mathrm{CABG}=$ coronary artery bypass grafting \\ $\mathrm{LVEF}=$ left ventricular ejection fraction}

replacement. ${ }^{5,7}$ As the overall cardiac surgery patient population becomes older and sicker, it is important to understand the impact of specific risk factors on the outcomes of specific procedures. Consequently, we reviewed our own institutional experience to better understand early postoperative outcomes in patients with low LVEF undergoing ARR.

\section{MATERIALS AND METHODS}

The Columbia University Medical Center institutional review board approved this study and waived the requirement for informed consent.

\section{Patient Selection}

All patients who underwent ARR at our institution between 2005 and 2013 were retrospectively reviewed. A total of 595 patients were identified and included in the study.

A restricted cubic spline analysis with 4 knots was conducted to clarify the possible nonlinear association between LVEF and mortality and to see whether any significant hazard changes occur at certain LVEF values. This analysis showed a relatively linear inverse relationship between LVEF and the hazard ratio for death in patients with an LVEF $<50 \%$ with no unique cutoff ejection fraction at which this association changes (Figure 1). To further illustrate the impact of reduced LVEF on mortality across the population, the patients were then divided into 3 groups by their LVEF (LVEF $<40 \%$, LVEF $40 \%-49 \%$, and LVEF $\geq 50 \%$ ). These categories coincide with the 2013 American College of Cardiology Foundation/American Heart Association categorizations of LVEF as reduced, borderline, and preserved. ${ }^{8}$

Clinical, follow-up, and mortality data were collected from our institutional electronic medical record. Mortality data for patients lost to followup were collected from the Social Security Death Index through 2014, after which survival data were only available via our institutional medical record. Baseline demographics, echocardiographic data, comorbidities, concomitant procedures, perioperative complications, postoperative complications, length of overall hospital and intensive care unit stay, and survival data were collected for analysis.

\section{Operative Methods}

Patients were cannulated for cardiopulmonary bypass using a strategy specifically tailored to the surgical indication, including information from both preoperative computed tomography scans and measurements from the intraoperative transesophageal echocardiogram. The operating surgeon determined whether axillary artery cannulation was used for selective, antegrade cerebral perfusion, as well as whether to spare the aortic valve. For patients undergoing only ARR or aortic root plus ascending aorta replacement, the standard, central cannulation strategy was used. Valvesparing procedures were performed using the reimplantation technique with a Gelweave Valsalva graft (Vascutek, Renfrewshire, Scotland). Composite bioprosthetics were constructed by sewing a stented biological aortic prosthesis to the skirt of the Valsalva graft (Video 1). ${ }^{9,10}$

\section{Statistical Analysis}

All analyses were performed using STATA 13.1 (StataCorp LP, College Station, Tex) or R v3.5.1 (R Foundation for Statistical Computing, Vienna,

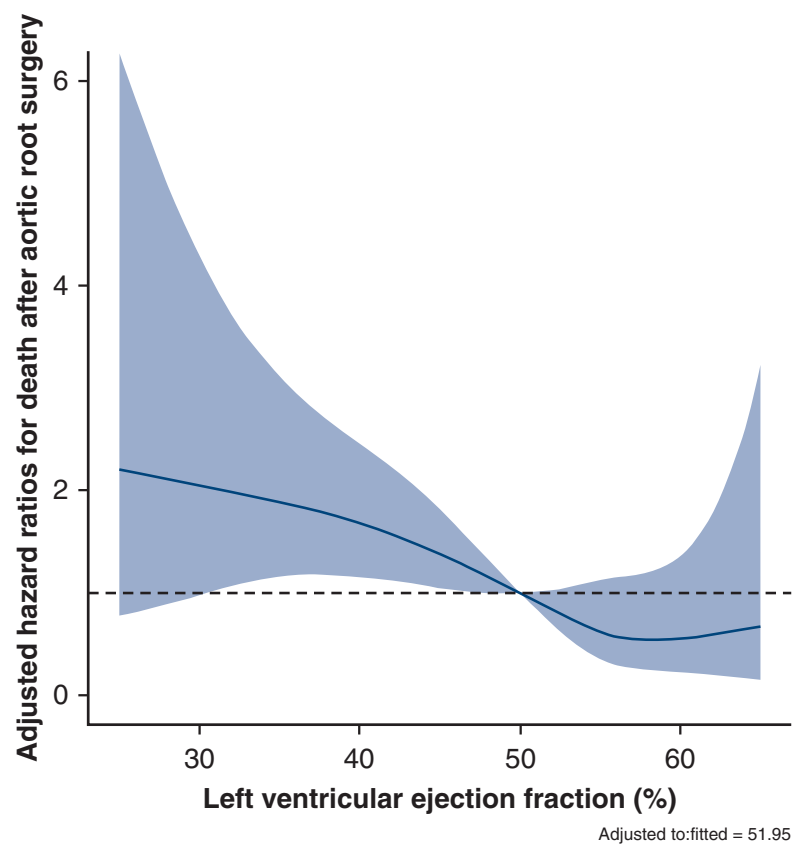

FIGURE 1. Adjusted restricted cubic spline curves with $95 \%$ confidence bands for hazard ratios of death with respect to patient left ventricular ejection fraction after aortic root replacement. Reference ejection fraction $50 \%$.

Austria) software. Continuous variables are presented as median and interquartile range and were compared using the Kruskal-Wallis test. Categorical data are presented as number and percentage of the total and compared using the Pearson $\chi^{2}$ test. Kaplan-Meier analysis was used to assess survival, with the equivalence of the survivor functions of the 3 groups assessed using the log-rank test. In a post-hoc power analysis with a sample size of 47 and sampling ratio of 11 (ie, 520/47), the power to detect a difference in in-hospital mortality ( $2 \%$ vs $12 \%$ ) was approximately 0.55 with a level of significance of 0.05 . Data were complete for preoperative LVEF, as well as perioperative morbidity and mortality. Any other missing data were replaced by multiple imputation methods using predictive mean matching.

To identify preoperative variables associated with mortality, univariable and multivariable Cox proportional hazards regression was performed and hazard ratios for death after root surgery were calculated with their $95 \%$ confidence intervals. The model included the following 12 covariates:

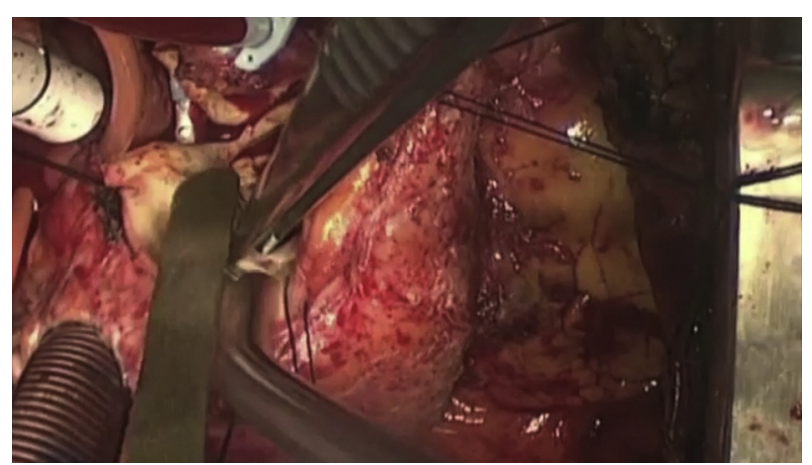

VIDEO 1. Intraoperative video showing aortic root replacement using a biological valved conduit. Video available at: https://www.jtcvs.org/ article/S0022-5223(18)32971-4/fulltext. 
TABLE 1. Patient demographics and baseline characteristics

\begin{tabular}{|c|c|c|c|c|}
\hline Patient demographics & LVEF $<\mathbf{4 0} \%(\mathbf{n}=\mathbf{5 0})$ & LVEF $40 \%-49 \%(n=60)$ & LVEF $\geq 50 \%(n=485)$ & $\boldsymbol{P}$ \\
\hline Age, y & $64.1(52.0-71.0)$ & $62.2(52.2-74.1)$ & $61.0(50.6-70.0)$ & .372 \\
\hline Male & $41(82.0)$ & $52(86.7)$ & $386(79.6)$ & .410 \\
\hline Body mass index, $\mathrm{kg} / \mathrm{m}^{2}$ & $26.2(23.5-28.7)$ & $26.0(24.1-28.9)$ & $27.2(24.5-30.5)$ & .055 \\
\hline \multicolumn{5}{|l|}{ Comorbidities } \\
\hline Hypertension & $30(60.0)$ & $39(65.0)$ & $324(66.8)$ & .616 \\
\hline Diabetes mellitus & $11(22.0)$ & $5(8.3)$ & $41(8.4)$ & .008 \\
\hline Coronary artery disease & $12(24.0)$ & $17(28.3)$ & $107(22.1)$ & .540 \\
\hline Cerebrovascular disease & $4(8.0)$ & $2(3.3)$ & $34(7.0)$ & .524 \\
\hline Chronic obstructive pulmonary disease & $4(8.0)$ & $4(6.7)$ & $25(5.1)$ & .650 \\
\hline End-stage renal disease & $2(4.0)$ & $0(0.0)$ & $1(0.2)$ & .001 \\
\hline Peripheral vascular disease & $0(0.0)$ & $0(0.0)$ & $14(2.9)$ & .197 \\
\hline Previous myocardial infarction & $5(10.0)$ & $4(6.7)$ & $21(4.3)$ & .182 \\
\hline Atrial fibrillation & $12(24.0)$ & 13 (21.7) & $63(13.0)$ & .032 \\
\hline Previous cardiac surgery & $11(22.0)$ & $10(16.7)$ & $69(14.2)$ & .324 \\
\hline \multicolumn{5}{|l|}{ Aortic dimensions, $\mathrm{mm}$} \\
\hline Aortic root diameter & $44.0(38.0-52.0)$ & $48.0(42.0-55.0)$ & $46.0(40.0-52.0)$ & .123 \\
\hline Ascending aortic diameter & $50.5(46.0-60.0)$ & $55.0(49.0-60.0)$ & $51.0(47.0-57.0)$ & .080 \\
\hline \multicolumn{5}{|l|}{ Echocardiographic data } \\
\hline LVEF, \% & $30.0(25.0-34.0)$ & $44.0(44.0-44.5)$ & $55.0(54.0-55.0)$ & .000 \\
\hline Aortic insufficiency* & $2.0(1.0-3.0)$ & $2.0(1.0-4.0)$ & $2.0(0.0-3.0)$ & .000 \\
\hline Bicuspid aortic valve & $19(38.0)$ & $22(36.7)$ & $233(48.0)$ & .118 \\
\hline
\end{tabular}

Data presented as number (\%) or median (interquartile range). $L V E F$, Left ventricular ejection fraction. *Valve insufficiency scale: 0 (none/trace) to 4 (severe).

age, male sex, body mass index, hypertension, diabetes, coronary artery disease, chronic kidney disease, LVEF, grade of aortic insufficiency, type A aortic dissection, history of previous cardiac surgery, and atrial fibrillation. Potential predictors were identified using a stepwise model building method to minimize the Akaike information criterion. To clarify the possible nonlinear association between LVEF and HRs for mortality, we used a restricted cubic spline model with 4 knots to determine whether there were any significant hazard changes at specific LVEF values. To adjust for baseline profiles, we calculated a generalized propensity score (ie, predicted LVEF) by a linear regression including 11 covariates (same as listed previously, excepting LVEF), by making LVEF a dependent variable. This score was then added to the model to predict survival outcomes. To assess the potential impact of presenting pathology on outcomes, a subgroup analysis was performed in only those patients who presented with an aortic root aneurysm. Two-tailed $P$ values of less than .05 were considered to be statistically significant for all tests.

\section{RESULTS}

\section{Patient Characteristics}

Patient demographics and baseline characteristics are presented in Table 1 . There were no differences in age, body mass index, or sex composition between the 2 groups. The prevalence of significant medical comorbidities, including coronary artery disease, history of stroke/ transient ischemic attack, and chronic obstructive pulmonary disease, were also similar; however, the rates of diabetes, end-stage renal disease, and atrial fibrillation increased with decreasing LVEF. There was no difference in the proportion of patients in each group with a history of previous cardiac surgery, and the diameter of both the aortic root and the ascending aorta were similar. The number of patients with a bicuspid aortic valve was also similar across the groups.

\section{Operative Indications and Details}

The indications for surgery and details of the performed procedures are listed in Table 2. Significant differences existed in the indications for surgery between the 2 groups. Although the majority of patients in both groups presented with an aortic root aneurysm, aneurysm was less common in patients with LVEF $<40 \%$ (74\% LVEF $<40 \%$ vs $91.7 \%$ LVEF $40 \%-49 \%$ vs $87.6 \%$ LVEF $\geq 50 \%$ ), and a greater percentage of patients with LVEF $<40 \%$ presented with Stanford type A aortic dissection (18\% LVEF $<40 \%$ vs $5.0 \%$ LVEF $40 \%-40 \%$ vs $10.3 \%$ LVEF $\geq 50 \%$ ) or infective endocarditis $(8.0 \% \mathrm{LVEF}<40 \%$ vs $3.3 \% \mathrm{LVEF}$ $40 \%-49 \%$ vs $1.0 \%$ LVEF $\geq 50 \%$ ) (overall $P=.003$ ). The aortic root was replaced using a valve-sparing procedure in $227(38.1 \%)$ patients, a stentless bioprosthesis in $214(36.0 \%)$ patients, a stented bioprosthesis in 137 $(23.0 \%)$ patients, a mechanical prosthesis in $10(1.7 \%)$ patients, and an aortic homograft in $7(1.2 \%)$ patients. A stented bioprosthesis, stentless bioprosthesis, mechanical prosthesis, or homograft was used more often in patients with lower LVEF, and they likewise underwent fewer valve-sparing procedures (overall $P<.001$ ).

The rate of concomitant procedures, including ascending aorta, hemiarch, or total arch replacement, as 
TABLE 2. Operative details

\begin{tabular}{|c|c|c|c|c|}
\hline Operative details & $\begin{array}{c}\text { LVEF }<\mathbf{4 0} \% \\
(n=50)\end{array}$ & $\begin{array}{l}\text { LVEF } 40 \%-49 \% \\
\quad(n=60)\end{array}$ & $\begin{array}{c}\text { LVEF } \geq \mathbf{5 0} \% \\
(\mathrm{n}=\mathbf{4 8 5})\end{array}$ & $\boldsymbol{P}$ \\
\hline Indication for surgery & & & & .003 \\
\hline Stanford type A dissection & $9(18)$ & $3(5.0)$ & $50(10.3)$ & \\
\hline Thoracic aortic aneurysm & $37(74.0)$ & $55(91.7)$ & $425(87.6)$ & \\
\hline Infective endocarditis & $4(8.0)$ & $2(3.3)$ & $5(1.0)$ & \\
\hline Other & $0(0.0)$ & $0(0.0)$ & $5(1.0)$ & \\
\hline Root replacement procedure & & & & .000 \\
\hline Stented bioprosthesis & $18(36.0)$ & $17(28.3)$ & $102(21.0)$ & \\
\hline Stentless bioprosthesis & $17(34.0)$ & $27(45.0)$ & $170(35.0)$ & \\
\hline Valve-sparing procedure & $10(20.0)$ & $13(21.7)$ & $204(42.1)$ & \\
\hline Mechanical bioprosthesis & $2(4.0)$ & $2(3.3)$ & $6(1.2)$ & \\
\hline Aortic homograft & $3(6.0)$ & $1(1.7)$ & $3(0.6)$ & \\
\hline \multicolumn{5}{|l|}{ Concomitant procedures } \\
\hline Ascending aorta replacement & $30(60.0)$ & $34(56.7)$ & $339(69.9)$ & .056 \\
\hline Aortic arch replacement & $11(22.0)$ & $10(16.7)$ & $67(13.8)$ & .273 \\
\hline Hemiarch replacement & $14(28.0)$ & $25(41.2)$ & $169(34.8)$ & .324 \\
\hline Coronary artery bypass grafting & $8(16.0)$ & $13(21.7)$ & $74(15.3)$ & 442 \\
\hline Mitral valve repair/replacement & $7(14.0)$ & $10(16.7)$ & $26(5.4)$ & .001 \\
\hline \multicolumn{5}{|l|}{ Cardiopulmonary bypass details } \\
\hline Cardiopulmonary bypass time, min & $130.0(103.0-185.0)$ & $145.0(118.5-185.0)$ & $128.0(103.0-159.0)$ & .009 \\
\hline Aortic crossclamp time, min & $94.5(71.0-122-0)$ & $105.5(86.5-134.0)$ & $95.0(77.0-124.0)$ & .079 \\
\hline $\begin{array}{l}\text { Deep hypothermic circulatory arrest/antegrade cerebral } \\
\text { perfusion time, } \min \end{array}$ & $12.0(9.0-17.0)$ & $11.5(10.0-13.0)$ & $11.0(9.0-15.0)$ & .716 \\
\hline Cerebral protection & & & & .820 \\
\hline Not needed & $21(42.0)$ & $23(38.3)$ & $221(45.6)$ & \\
\hline Deep hypothermic circulatory arrest & $0(0.0)$ & $0(0.0)$ & $1(0.2)$ & \\
\hline Antegrade cerebral perfusion & $29(58.0)$ & 37 (61.7) & $263(54.2)$ & \\
\hline
\end{tabular}

Data expressed as number (\%) or median (interquartile range). $L V E F$, Left ventricular ejection fraction.

well as coronary artery bypass grafting (CABG) was similar between the groups. Patients with a LVEF $<50 \%$ underwent more mitral valve procedures $(14.0 \% \mathrm{LVEF}$ $<40 \%$ vs $16.7 \%$ LVEF $40 \%-40 \%$, vs $5.4 \%$ LVEF $\geq 50 \%, P=.001)$. A majority of patients in each group received antegrade selective cerebral perfusion $(58.0 \%$ LVEF $<40 \%$ vs $61.7 \%$ LVEF $40 \%-49 \%$ vs $54.2 \%$ LVEF $\geq 50 \%$ ). Only one patient, who had a LVEF $\geq 50 \%$, required deep hypothermic circulatory arrest. The duration of cardiopulmonary bypass was greatest in patients with a LVEF 40\%-49\% (130 minutes LVEF $<40$ vs 145 minutes LVEF $40 \%-49 \%$ vs 128 minutes LVEF $\geq 50 \%, P=.009$ ). There was no difference in aortic crossclamp or antegrade cerebral perfusion/deep hypothermic circulatory arrest duration between the groups.

\section{Postoperative Outcomes}

Postoperative outcomes are presented in Table 3. Inhospital mortality was $14.0 \%$ in patients with an LVEF $<40 \%$ compared with $5.0 \%$ in patients whose LVEF was $40 \%$ to $49 \%$ and $1.0 \%$ in patients with an LVEF $\geq 50 \%$ $(P<.001)$. Of the 15 patients who died during their index hospitalization, 4 died of cardiogenic shock, 4 of postoperative stroke, 2 of multisystem organ failure, 2 of malignant arrhythmias, 1 of septic shock, 1 of hypovolemic shock, and 1 from pulmonary embolism.

Significantly more patients with decreased LVEF developed respiratory failure $(16.0 \%$ LVEF $<40 \%$ vs $6.7 \%$ LVEF $40 \%-49 \%$ vs $4.9 \%$ LVEF $\geq 50 \%$, $P=.008)$. Reoperation to control bleeding was also more common in patients with the lowest LVEF (18.0\% LVEF $<40 \%$ vs $5.0 \%$ LVEF $40 \%-49 \%$ vs $5.8 \%$ LVEF $\geq 50 \%$, $P=.004)$. The postoperative need for mechanical circulatory support was greater in patients with lower LVEF $(8.0 \%$ LVEF $<40 \%$ vs $5.0 \%$ LVEF $40 \%-49 \%$ vs $1.4 \% \mathrm{LVEF} \geq 50 \%, P=.005)$. There were no differences in the rates of stroke, myocardial infarction, atrial fibrillation, or the need for a new permanent pacemaker. In addition to greater in-hospital death and perioperative morbidity, patients with lower LVEF spent significantly more time both in the hospital and in the intensive care unit.

Using a Cox proportional hazards regression, we identified decreased LVEF, age, a history of previous cardiac surgery, and a surgical indication of type A aortic dissection as independent predictors of mortality (Table 4). Kaplan-Meier survival analysis (Figure 2) demonstrated a difference between the survival curves of the 3 groups at up to 6 years $(\log$-rank $P<.001)$. 
TABLE 3. Postoperative outcomes

\begin{tabular}{|c|c|c|c|c|}
\hline Outcomes & LVEF $<\mathbf{4 0} \%(\mathbf{n}=\mathbf{5 0})$ & LVEF $40 \%-49 \%(n=60)$ & LVEF $\geq \mathbf{5 0} \%(\mathbf{n}=\mathbf{4 8 5})$ & $\boldsymbol{P}$ \\
\hline Intraoperative death & $0(0.0)$ & $1(1.7)$ & $0(0.0)$ & - \\
\hline In-hospital death & $7(14.0)$ & $3(5.0)$ & $5(1.0)$ & .000 \\
\hline Hospital length of stay, $d$ & $10.5(7.0-19.0)$ & $8.0(5.0-11.5)$ & $6.0(5.0-9.0)$ & $<.001$ \\
\hline Intensive care unit length of stay, $d$ & $4.0(2.0-8.0)$ & $2.0(1.0-4.0)$ & $2.0(1.0-4.0)$ & $<.001$ \\
\hline \multicolumn{5}{|l|}{ Postoperative complications } \\
\hline Reoperation for bleeding & $9(18.0)$ & $3(5.0)$ & $28(5.8)$ & .004 \\
\hline Stroke & $4(8.0)$ & $1(1.7)$ & $19(3.9)$ & .233 \\
\hline Respiratory failure & $8(16.0)$ & $4(6.7)$ & 24 (4.9) & .008 \\
\hline New need for dialysis & $4(8.0)$ & $1(1.7)$ & $11(2.3)$ & .051 \\
\hline Myocardial infarction & $0(0.0)$ & $0(0.0)$ & $4(0.8)$ & .633 \\
\hline Atrial fibrillation & $24(48.0)$ & $21(35.0)$ & $192(39.6)$ & .370 \\
\hline New pacemaker requirement & $3(6.0)$ & $3(5.0)$ & $26(5.4)$ & .973 \\
\hline Aortic reoperation & $3(6.0)$ & $5(8.3)$ & $25(5.1)$ & .591 \\
\hline Need for mechanical circulatory support & $4(8.0)$ & $3(5.0)$ & $7(1.4)$ & .005 \\
\hline
\end{tabular}

Data presented as number (\%), median (interquartile range). $L V E F$, Left ventricular ejection fraction.

A subgroup analysis of only those patients who underwent ARR for aortic root aneurysm found a similar increase in the rates of mortality and major morbidities in patients with lower LVEF (Table E1). The rates of in-hospital death (8.1\% LVEF $<40 \%$ vs $3.6 \%$ LVEF $40 \%-49 \%$ vs $0.7 \%$ LVEF $\geq 50 \%, P=.001$ ), reoperation for bleeding (16.2\% LVEF $<40 \%$ vs $3.6 \%$ LVEF $40 \%-49 \%$ vs $8.7 \%$ LVEF $\geq 50 \%, P=.014)$, respiratory failure $(13.5 \%$ LVEF $<40 \%$ vs $3.6 \%$ LVEF $40 \%-49 \%$ vs $3.3 \%$ LVEF $\geq 50 \%, P=.010$ ), need for new continuous renalreplacement therapy $(8.1 \%$ LVEF $<40 \%$ vs $0.0 \%$ LVEF $40 \%-49 \%$ vs $1.4 \%$ LVEF $\geq 50 \%, P=.007$ ), and need for postoperative mechanical circulatory support (5.4\% LVEF $<40 \%$ vs $3.6 \%$ LVEF $40 \%-49 \%$ vs $0.5 \%$ LVEF $\geq 50 \%, P=.005$ ) were increased in patients with lower LVEF. Hospital and ICU length of stay also were increased.

\section{DISCUSSION}

Overall outcomes after ARR procedures are excellent. ${ }^{5,11}$ However, with the population of cardiac surgery patients becoming older and sicker, ever-greater risk cases are being referred for surgical intervention. As aortic surgery is often prophylactic, it is imperative that the risk of a future aortic event, such as dissection or aneurysm rupture, is weighed against the risk of operation when counseling patients. Left ventricular dysfunction is a known risk factor in both CABG and valve surgery. ${ }^{12-14}$ However, to date, there are no studies specifically examining the impact of a low LVEF on outcomes after ARR. Rather, previous series have either examined outcomes in patients deemed to be at overall increased risk, or used functional metrics, such as New York Heart Association class, in their analysis. Consequently, we retrospectively reviewed our institutional experience to better understand the specific

TABLE 4. Cox proportional hazards regression analysis for preoperative characteristics predictive of mortality

\begin{tabular}{|c|c|c|c|c|}
\hline \multirow[b]{2}{*}{ Variables } & \multicolumn{2}{|c|}{ Univariable } & \multicolumn{2}{|c|}{ Multivariable } \\
\hline & HR $(95 \%$ CI $)$ & $P$ value & HR $(95 \%$ CI $)$ & $P$ value \\
\hline LVEF & $0.94(0.92-0.97)$ & $<.001$ & $0.96(0.94-0.99)$ & .010 \\
\hline Age & $1.05(1.02-1.08)$ & $<.001$ & $1.03(1.01-1.07)$ & .010 \\
\hline Male & $0.62(0.29-1.34)$ & .221 & - & - \\
\hline Body mass index & $0.93(0.85-1.00)$ & .063 & - & - \\
\hline Diabetes mellitus & $1.81(0.70-4.70)$ & .223 & - & - \\
\hline Hypertension & $1.37(0.64-2.98)$ & .416 & - & - \\
\hline CKD (creatinine $>2.0$ ) & $5.10(1.22-21.34)$ & .026 & - & - \\
\hline Coronary artery disease & $1.77(0.85-3.67)$ & .125 & & \\
\hline Atrial fibrillation & $2.79(1.32-5.91)$ & .007 & $1.81(0.83-3.94)$ & .134 \\
\hline Aortic insufficiency & $1.15(0.90-1.47)$ & .273 & $1.22(0.94-1.59)$ & .138 \\
\hline Previous cardiac surgery & $3.23(1.56-6.71)$ & .002 & $2.93(1.38-6.19)$ & .005 \\
\hline Type A dissection & $4.90(2.36-10.19)$ & $<.001$ & $4.02(1.88-8.59)$ & $<.001$ \\
\hline
\end{tabular}

$H R$, Hazard ratio; $C I$, confidence interval; $L V E F$, left ventricular ejection fraction; $C K D$, chronic kidney disease. 


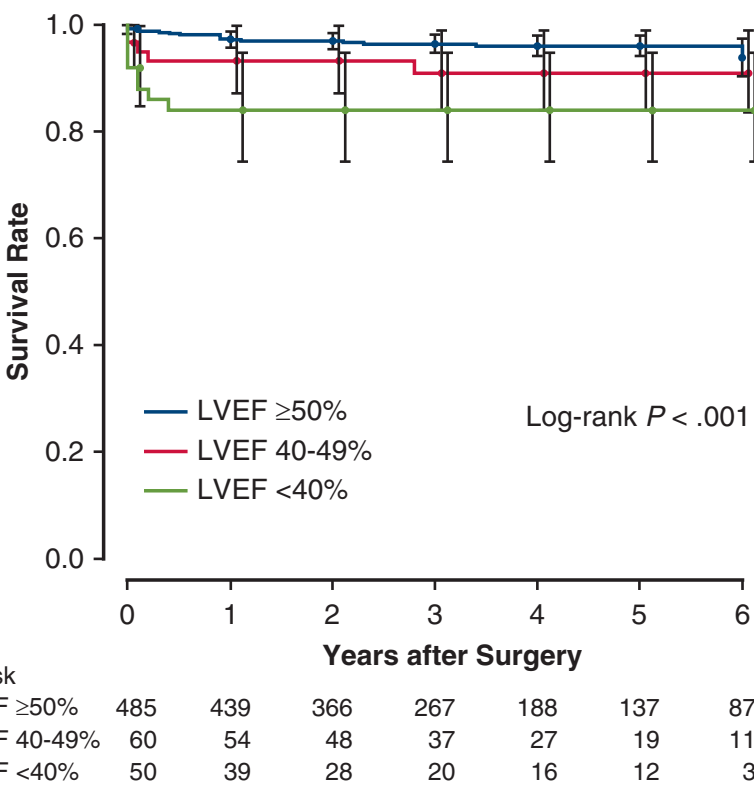

FIGURE 2. Kaplan-Meier analysis of survival by LVEF: LVEF $<40 \%$ (green line), LVEF $40 \%-49 \%$ (red line), LVEF $\geq 50 \%$ (blue line). Bars represent $95 \%$ confidence intervals. Patients at risk at each time point are presented in the table at bottom. $L V E F$, Left ventricular ejection fraction.

impact of LVEF on outcomes after ARR, finding that patients with decreased LVEF are at significantly greater risk for mortality and perioperative morbidity, as well as increased hospital and intensive care unit length of stay.

Overall in-hospital mortality in our series was $2.5 \%$, which is consistent with the best outcomes from previously reported series. ${ }^{5,11}$ However, patients with a LVEF $<40 \%$ had a significantly greater early mortality of $14 \%$ compared with only $1.0 \%$ in patients with a LVEF of at least $50 \%$. Although a low LVEF is known to increase surgical risk in patients undergoing $\mathrm{CABG}$ and valve procedures, previous studies have shown that these procedures can be performed safely and with an acceptable increase in mortality. ${ }^{15-19}$ In their large, multicenter study, for example, Topkara and colleagues ${ }^{16}$ reported in-hospital mortality of $6.5 \%$ for patients with a LVEF $<20 \%$ undergoing CABG compared with $1.4 \%$ for those patients with a LVEF $>40 \%$. As a result of such data, CABG and valve procedures are appropriately offered to patients with substantial left ventricular dysfunction. The much greater increase in mortality seen in patients with low LVEF undergoing ARR, however, highlights the complexity of these operations, underscoring the fact that significantly decreased left ventricular function does not impact all patients equally.

In addition to increased mortality, patients with a decreased LVEF also had greater rates of perioperative morbidity. This is consistent with previous studies of patients with low LVEF undergoing cardiac surgery, which have shown an increased risk of low cardiac output syndrome and need for inotropic support, acute renal failure, prolonged respiratory failure, atrial fibrillation, stroke, sepsis, deep sternal wound infection, and bleeding requiring reoperation. ${ }^{16,20-23}$ In our series, patients with a LVEF $<40 \%$ had a notably greater rate of reoperation for bleeding, as well as increased rates of respiratory failure and postoperative mechanical circulatory support. Furthermore, there was a significant increase in both intensive care unit and overall hospital length of stay. Interestingly, the significant increase in reoperation for bleeding seen in the patients with the lowest LVEF is consistent with studies of patients with reduced LVEF undergoing CABG. ${ }^{16}$ However, there is no obvious underlying cause, and this is a potential area for further study.

Williams and colleagues ${ }^{5}$ found that patients who undergo nonelective ascending aorta and arch procedures have significantly worse outcomes when compared with patients whose repairs are performed electively. This is consistent with the known, substantial risk associated with repair of acute aortic syndromes, especially in patients with significant malperfusion syndromes, who have been subclassified and specifically risk stratified by several other groups. $^{24,25}$ In our experience, a significantly greater percentage of patients with a decreased LVEF had a nonelective indication for ARR, specifically Stanford type A dissection or endocarditis, and it is possible that this contributed to the decreased early survival seen in the low LVEF group. However, a subgroup analysis of only those patients who underwent surgery for aneurysmal disease found similarly increased rates of early mortality and significant morbidity. This suggests that although urgent or emergent surgical indications further increase operative risk, they do not account for the marked increase in morbidity and mortality seen in patients with low LVEF.

When considering any patient for ARR, the primary question guiding management should be whether the risk of a future aortic event, such as dissection or rupture, outweighs the risk of surgical repair. Currently, guidelines recommend elective repair of root, ascending, and arch aneurysms measuring $>5.5 \mathrm{~cm}$ in patients without a genetic aortopathy or alternative indication for cardiac surgery. ${ }^{26}$ This recommendation is based on the observation that the risk of aneurysm rupture, dissection, or death exceeds operative mortality at this aneurysm size, assuming an operative mortality of $5 \% .^{5}$ However, in this study we found that in patients with aneurysmal disease and a LVEF $<40 \%$, early mortality was $8 \%$, and the rate of major morbidity was $13.9 \%$. Importantly, the restricted spline analysis showed an approximately inversely linear correlation between LVEF and outcomes, so while LVEF categories were used to help illustrate the impact of reduced LVEF across the study population, it is important to realize 
that operative risk rises as the ejection fraction falls once the LVEF falls below the normal range. Consequently, size-based guidelines should be considered in the overall context of the patient when there are major risk factors for adverse outcomes, such as significant left ventricular dysfunction. We do not propose that any absolute LVEF valve be used to establish surgical candidacy, but rather that, especially in elective cases, the risk of a prophylactic operation be weighed against its risks. In some cases, continued surveillance may be warranted in patients with aneurysms that meet standard size criteria for intervention.

This study has several important limitations. First, it is necessarily limited by its retrospective, single-institution design, and as a single-center study, it reflects our own institutional treatment biases. Second, the sample size for patients with a LVEF $<50 \%$ is comparatively small, rendering the study underpowered to detect differences in uncommon clinical events. This was addressed as much as possible by designing the study to focus on mid-term mortality during follow-up rather than aiming to parse out detailed differences between groups with limited patient numbers. For example, the contribution of malperfusion syndromes to outcomes within the subset of patients with an aortic dissection, as well as other potentially interesting subgroup analyses, were outside of the scope of this study.

Left ventricular dysfunction is a complex condition with multiple potential etiologies that do not all respond similarly to medical or surgical therapy. Although the etiology of left ventricular dysfunction in this population is most likely to be severe aortic valve dysfunction, different causes of left ventricular dysfunction could play a role in postoperative outcomes and further study of their specific impact is warranted. Because high-quality, long-term follow-up data were limited, especially by our need to use the Social Security Death Index for patients lost to follow-up, this study was designed to compare mid-term mortality during the period where the most complete follow-up data were available, and therefore we are unable to comment on the longterm results in these patients. Finally, postoperative quality of life is an important consideration when proposing highrisk surgery, and we do not have data on the postoperative quality of life for these patients.

In conclusion, we found that patients with a reduced LVEF who undergo ARR had significantly increased midterm mortality, as well as in-hospital mortality and major perioperative morbidity when compared with patients with a LVEF $>50 \%$. Furthermore, this increased risk is not due to high-risk surgical indications or associated comorbidities but rather likely reflects the inherent risk of performing cardiac surgery in patients with pre-existing left ventricular dysfunction. The significantly higher mid-term mortality, in-hospital mortality, and major morbidity should be addressed when counseling patients with low LVEF who need aortic root replacement and may be considered when evaluating size-based criteria for elective aneurysm repair in the future.

\section{Conflict of Interest Statement}

Dr George is a consultant for Edwards Lifesciences and Medtronic. All other authors have nothing to disclose with regard to commercial support.

\section{References}

1. Arabkhani B, Mookhoek A, Di Centa I, Lansac E, Bekkers JA, Van Wijngaarden RDL, et al. Reported outcome after valve-sparing aortic root replacement for aortic root aneurysm: a systematic review and meta-analysis. Ann Thorac Surg. 2015;100:1126-31.

2. Krähenbühl ES, Immer FF, Stalder M, Englberger L, Eckstein FS, Schmidli J, et al. Technical advances improved outcome in patients undergoing surgery of the ascending aorta and/or aortic arch: ten years experience. Eur J Cardiothorac Surg. 2008;34:595-9.

3. Zehr KJ, Orszulak TA, Mullany CJ, Matloobi A, Daly RC, Dearani JA, et al. Surgery for aneurysms of the aortic root: a 30-year experience. Circulation. 2004; 110:1364-71.

4. Stamou SC, Williams ML, Gunn TM, Hagberg RC, Lobdell KW, Kouchoukos NT. Aortic root surgery in the United States: a report from the Society of Thoracic Surgeons database. J Thorac Cardiovasc Surg. 2015;149:116-22.e4.

5. Williams JB, Peterson ED, Zhao Y, O'Brien SM, Andersen ND, Miller DC, et al. Contemporary results for proximal aortic replacement in North America. J Am Coll Cardiol. 2012;60:1156-62.

6. David TE, Feindel CM, Webb GD, Colman JM, Armstrong S, Maganti M. Longterm results of aortic valve-sparing operations for aortic root aneurysm. J Thora Cardiovasc Surg. 2006;132:347-54.

7. Gaudino M, Lau C, Munjal M, Avgerinos D, Girardi LN. Contemporary outcomes of surgery for aortic root aneurysms: a propensity-matched comparison of valve-sparing and composite valve graft replacement. J Thorac Cardiovasc Surg. 2015; 150:1120-9.e1.

8. Yancy CW, Jessup M, Bozkurt B, Butler J, Casy DE, Drazner MH, et al. 2013 ACCF/AHA guideline for the management of heart failure. J Am Coll Cardiol. 2013;62:e147-239.

9. Tabata M, Takayama H, Bowdish ME, Smith CR, Stewart AS. Modified Bentall operation with bioprosthetic valved conduit: Columbia University experience. Ann Thorac Surg. 2009;87:1969-70.

10. Stewart AS, Takayama H, Smith CR. Modified Bentall operation with a novel biologic valved conduit. Ann Thorac Surg. 2010;89:938-41.

11. Caceres M, Ma Y, Rankin JS, Saha-Chaudhuri P, Englum BR, Gammie JS, et al. Mortality characteristics of aortic root surgery in North America. Eur J Cardiothorac Surg. 2014;46:887-93.

12. Cohn PF, Gorlin R, Cohn LH, Collins JJ. Left ventricular ejection fraction as a prognostic guide in surgical treatment of coronary and valvular heart disease. Am J Cardiol. 1974;34:136-41.

13. Roques F, Nashef SA, Michel P, Gauducheau E, de Vincentiis C, Baudet E, et al. Risk factors and outcome in European cardiac surgery: analysis of the EuroSCORE multinational database of 19030 patients. Eur J Cardiothorac Surg. 1999; 15:816-23.

14. Forman R, Firth BG, Barnard MS. Prognostic significance of preoperative left ventricular ejection fraction and valve lesion in patients with aortic valve replacement. Am J Cardiol. 1980;45:1120-5.

15. Pieri M, Belletti A, Monaco F, Pisano A, Musu M, Dalessandro V, et al. Outcome of cardiac surgery in patients with low preoperative ejection fraction. BMC Anesthesiol. 2016;16.

16. Topkara VK, Cheema FH, Kesavaramanujam S, Mercando ML, Cheema AF, Namerow PB, et al. Coronary artery bypass grafting in patients with low ejection fraction. Circulation. 2005;112(9 suppl):1344-50.

17. Halkos ME, Chen EP, Sarin EL, Kilgo P, Thourani VH, Lattouf OM, et al. Aortic valve replacement for aortic stenosis in patients with left ventricular dysfunction. Ann Thorac Surg. 2009;88:746-51.

18. Maltais S, Schaff HV, Daly RC, Suri RM, Dearani JA, Sundt TM, et al. Mitral regurgitation surgery in patients with ischemic cardiomyopathy and ischemic 
mitral regurgitation: factors that influence survival. J Thorac Cardiovasc Surg. 2011;142:995-1001.

19. Parker JA, Kennes LN, Ruckert J, Dahm M, Vahl C-F. Outcome after mitral valve operations with depressed left ventricular function. Asian Cardiovasc Thorac Ann. 2012;20:292-8.

20. Butterworth JF, Legault C, Royster RL, Hammon JW. Factors that predict the use of positive inotropic drug support after cardiac valve surgery. Anesth Analg. 1998:86:461-7.

21. Thakar CV, Arrigain S, Worley S, Yared J-P, Paganini EP. A clinical score to predict acute renal failure after cardiac surgery. J Am Soc Nephrol. 2005:16:162-8.

22. Bove T, Calabrò MG, Landoni G, Aletti G, Marino G, Crescenzi G, et al. The incidence and risk of acute renal failure after cardiac surgery. $J$ Cardiothorac Vasc Anesth. 2004;18:442-5.

23. Mariscalco G, Biancari F, Zanobini M, Cottini M, Piffaretti G, Saccocci M, et al. Bedside tool for predicting the risk of postoperative atrial fibrillation after cardiac surgery: the POAF score. J Am Heart Assoc. 2014;3:e000752.
24. Kimura N, Ohnuma T, Itoh S, Sasabuchi Y, Asaka K, Shiotsuka J, et al. Utility of the Penn classification in predicting outcomes of surgery for acute type A aortic dissection. Am J Cardiol. 2014;113:724-30.

25. Mejàre-Berggren $\mathrm{H}$, Olsson $\mathrm{C}$. Validation and adjustment of the LeipzigHalifax acute aortic dissection type A scorecard. Ann Thorac Surg. 2017; 104:1577-82

26. Hiratzka LF, Bakris GL, Beckman JA, Bersin RM, Carr VF, Casey DE Jr, et al. 2010 ACCF/AHA/AATS/ACR/ASA/SCA/SCAI/SIR/STS/SVM guidelines for the diagnosis and management of patients with thoracic aortic disease: executive summary. Anesth Analg. 2010;111:279-315.

Key Words: aortic root replacement, cardiac surgery, left ventricular ejection fraction, heart failure, outcomes, complications

Readers who found these articles interesting may also like to read the following papers found in recent and future issues of our sister publications, Seminars in Thoracic and Cardiovascular Surgery and Operative Techniques in Thoracic and Cardiovascular Surgery!

\section{Adult: Aorta}

Optimal Cerebral Protection Strategies in Aortic Surgery. Lou X, Chen EP. Semin Thorac Cardiovasc Surg. 2019 Summer;31(2):146-152.

The Double-Barreled Endografting Technique in a Patient With Chronic Type B Aortic Dissection. Masada K, Kuratani T, Shimamura K, Sawa Y. Semin Thorac Cardiovasc Surg. 2019 Summer;31(2):183-186.

Commentary: Paving the Right Road? Estrera AL. Semin Thorac Cardiovasc Surg. 2019 Summer;31(2):187.

Use Side Branch of the Aortic Graft to Facilitate Coronary Reconstruction During Complex Aortic Surgery. Cheng YT, Leb JS, Bloom M, et al. Semin Thorac Cardiovasc Surg. 2019 Summer;31(2):201-206.

Commentary: What if “Cabrol” Lost Half of Its Mustache? Dagenais F. Semin Thorac Cardiovasc Surg. 2019 Summer;31(2):207-208. 


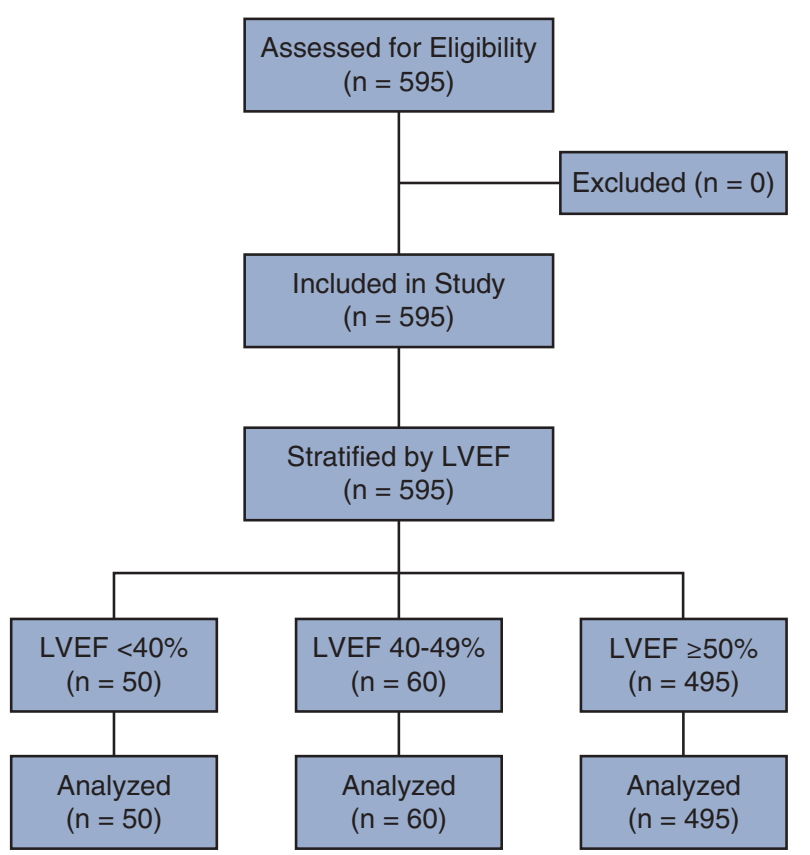

FIGURE E1. Patient flow diagram illustrating the study design. LVEF,

Left ventricular ejection fraction.

TABLE E1. Subgroup analysis of postoperative outcomes in only those patients who underwent aortic root replacement due to aneurysmal disease

\begin{tabular}{|c|c|c|c|c|}
\hline Outcomes & LVEF $<\mathbf{4 0} \%(n=37)$ & LVEF $40 \%-49 \%(n=55)$ & LVEF $\geq 50 \%(n=424)$ & $\boldsymbol{P}$ \\
\hline In-hospital death & $3(8.1)$ & $2(3.6)$ & $3(0.7)$ & .001 \\
\hline Hospital length of stay, $d$ & $10(7-15)$ & $7(5-10)$ & $6(5-8)$ & $<.001$ \\
\hline Intensive care unit length of stay, $d$ & $4(2-7)$ & $2(1-4)$ & $2(1-3)$ & $<.001$ \\
\hline \multicolumn{5}{|l|}{ Postoperative complications } \\
\hline Reoperation for bleeding & $6(16.2)$ & $2(3.6)$ & $21(8.7)$ & .014 \\
\hline Stroke & $3(8.1)$ & $0(0.0)$ & $11(2.6)$ & .060 \\
\hline Respiratory failure & $5(13.5)$ & $2(3.6)$ & $14(3.3)$ & .010 \\
\hline New need for dialysis & $3(8.1)$ & $0(0.0)$ & $6(1.4)$ & .007 \\
\hline Myocardial infarction & $0(0.0)$ & $0(0.0)$ & $3(7.1)$ & .721 \\
\hline Atrial fibrillation & $18(48.6)$ & $19(34.5)$ & $168(39.6)$ & .397 \\
\hline New pacemaker requirement & $2(5.4)$ & $2(3.6)$ & $22(5.2)$ & .880 \\
\hline Aortic reoperation & $2(5.4)$ & $5(9.1)$ & $21(4.9)$ & .444 \\
\hline Need for mechanical circulatory support & $2(5.4)$ & $2(3.6)$ & $2(0.5)$ & .005 \\
\hline
\end{tabular}

Data presented as number (\%) or median (interquartile range). $L V E F$, Left ventricular ejection fraction. 